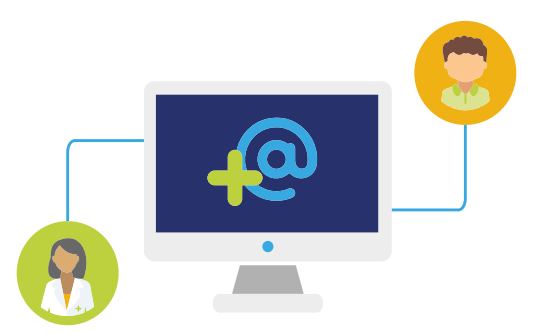

\title{
TELECONSULTORIA ASSÍNCRONA PARA FONOAUDIÓLOGOS DE CRIANÇAS COM DEFICIÊNCIA AUDITIVA: RELATO DE CASO
}

\author{
ASSYNCRONE TELECONSULTATION FOR HARD OF HEARING CHILDREN \\ SPEECH THERAPISTS: CASE REPORT
}

\begin{abstract}
Rafael Douglas de Sousa Maniçoba
Fonoaudiólogo. Egresso do Curso de Fonoaudiologia da Universidade Federal do Rio Grande do Norte.

E-mail: rafarn2009@hotmail.com

Sheila Andreoli Balen

Fonoaudióloga. Docente do Departamento de Fonoaudiologia da Universidade Federal do Rio Grande do Norte e do Programa Associado de Pós-Graduação em Fonoaudiologia UFRN-UFPB. Doutora em Psicologia-Neurociências e Comportamento pela Universidade de São Paulo. Pesquisadora do Laboratório de Inovação Tecnológica em Saúde (LAIS) da Universidade Federal do Rio Grande do Norte.

E-mail: sheila@sheilabalen@.com

Joseli Soares Brazorotto

Fonoaudióloga. Docente do Departamento de Fonoaudiologia da Universidade Federal do Rio Grande do Norte e do Mestrado Profissional em Gestão e Inovação em Saúde MPGIS/UFRN. Doutora em Educação Especial pela Universidade Federal de São Carlos. Pesquisadora do Laboratório de Inovação Tecnológica em Saúde (LAIS) da Universidade Federal do Rio Grande do Norte. E-mail: brazorotto@yahoo.com
\end{abstract}

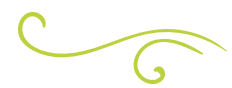

\section{RESUMO}

A formação de profissionais especializados na área da (re)habilitação auditiva para crianças com deficiência auditiva é um desafio que pode ser enfrentado com as ferramentas da Telessaúde. Neste sentido, os objetivos deste estudo de caso foram: avaliar o efeito da teleconsultoria assíncrona sobre a qualidade da terapia fonoaudiológica de crianças com deficiência auditiva, bem como analisar a satisfação dos fonoaudiólogos com a teleconsultoria no modelo assíncrono. A partir da análise de quinze sessões de terapias realizadas por duas fonoaudiólogas de um serviço de saúde auditiva do Rio Grande do Norte, credenciado ao Sistema Único de Saúde, foram comparados os escores do instrumento de análise da qualidade da sessão de terapia fonoaudiológica nos momentos pré e pós a teleconsultoria. A análise dos vídeos de terapia foi realizada por dois pesquisadores, de maneira independente e foi estabelecido o critério de confiabilidade para esta análise. Investigou-se também a satisfação dos fonoaudiólogos com o serviço de teleconsultoria oferecido. Os resultados indicaram índice de mudança confiável da qualidade das terapias fonoaudiológicas após as teleconsultorias assíncronas. Os fonoaudiólogos avaliaram positivamente a teleconsultoria assíncrona, indicando sua satisfação com a mesma. A teleconsultoria assíncrona produziu efeitos positivos nas 
terapias fonoaudiológicas analisadas, com a melhoria da qualidade do serviço ofertado às crianças com deficiência auditiva.

PALAVRAS-CHAVE: Fonoaudiologia. Deficiência Auditiva. Garantia da Qualidade dos Cuidados de Saúde.

\section{ABSTRACT}

The training of professionals specialized in the area of (re)habilitation for hard of hearing children is a challenge that can be faced with the tools of Telehealth. In this sense, the aims of this case study were: to evaluate the effect of the asynchronous teleconsulting on the quality of Aurioral therapy for hard of hearing children, as well as to analyze the satisfaction of speech therapists with teleconsulting in the asynchronous model. From the analysis of fifteen sessions of speech therapies of two speech therapists of a hearing health service of Rio Grande do Norte accredited to the Unified Health System, the scores of the instrument of quality analysis of Aurioral therapy were compared in the pre and post moments the teleconsulting. The analysis of the therapy videos was performed independently by two researchers and the reliability criterion was established for this analysis. It was also investigated the satisfaction of speech therapists with the teleconsulting service offered. The results indicated an index of reliable change in the quality of Aurioral therapy after asynchronous teleconsultation. Speech-language pathologists evaluated positively the asynchronous teleconsulting, indicating their satisfaction with it. The asynchronous teleconsulting produced positive effects in the Aurioral therapies analyzed, with the improvement of the quality of the service offered to hard of hearing children.

KEYWORDS: Telehealth. Hearing Loss. Speech. Language and Hearing Sciences. Quality Assurance. Health Care.

\section{INTRODUÇÃO}

Considerando os serviços prestados à população quanto à Saúde Auditiva, desde 2004, com a implementação da Política Nacional de Saúde Auditiva pelo Mistério da Saúde, faz-se necessária a avaliação dos serviços de saúde auditiva, tendo como objetivo acrescentar melhorias a esta política, assim otimizando a verba pública para o atendimento de qualidade a um maior número de indivíduos com deficiência auditiva (ARMIGLIATO et al., 2010).

Concernente à (re)habilitação auditiva ou a terapia fonoaudiológica para pessoas com deficiência auditiva, o Plano Nacional dos Direitos da Pessoa com Deficiência - Viver sem Limite, (BRASIL, 2013a), por meio da articulação de políticas governamentais de acesso à educação, inclusão social, atenção à saúde e acessibilidade, reitera a necessidade de ofertar serviços de qualidade à pessoa com deficiência. Especificamente no caso das pessoas com deficiência auditiva, a adaptação dos recursos auxiliares à audição (aparelhos auditivos, implantes cocleares, sistemas de FM e outros) é o início do processo de (re)habilitação auditiva, sendo necessária a terapia fonoaudiológica especializada para o bom aproveitamento destes recursos.

A qualidade da terapia fonoaudiológica para crianças com deficiência auditiva baseia-se na correta aplicação de procedimentos e técnicas, além do gerenciamento terapêutico sobre vários aspectos que envolvem o acompanhamento audiológico, o uso do dispositivo, a parceria entre a família, a escola e o fonoaudiólogo. (BEVILACQUA; FORMIGONI, 2012; CRUZ et al., 2013).

A avaliação da qualidade dos serviços de saúde aborda a análise de três seguimentos: a estrutura, o processo e os resultados. A avaliação da estrutura corresponde às condições físicas, aos equipamentos, aos materiais e aos profissionais presentes no serviço de saúde. Já a avaliação do processo corresponde ao conjunto de 
atividades desenvolvidas na relação profissional e paciente. Por sua vez, a avaliação dos resultados refere-se às mudanças verificadas na condição de saúde do paciente (ARMIGLIATO et al., 2010).

A análise da aplicação das técnicas e procedimentos para o desenvolvimento das habilidades auditivas e de linguagem oral para as crianças com deficiência auditiva é de extrema importância para a melhoria da qualidade da terapia fonoaudiológica, sendo esta uma proposta de avaliação dos processos de trabalho do fonoaudiólogo na (re)habilitação auditiva.

No Brasil, o modelo de terapia fonoaudiológica para crianças com deficiência auditiva mais utilizado é o Abordagem Aurioral e a área de estudo denomina-se Audiologia Educacional (BEVILACQUA; FORMIGONI, 2012). De acordo com tal abordagem, a terapia fonoaudiológica deve apresentar uma organização sistemática das metas, estratégias e técnicas apropriadas ao desempenho de cada bebê ou criança com deficiência auditiva. Assim, são descritas as principais estratégias e técnicas utilizadas na terapia, tais como: troca de turnos na comunicação/chamar e se despedir dos brinquedos; sinalizar expectativas; pista de mão/pista com o brinquedo para imitação; repetição; espera; questionamento; pausas; reformulação ou refraseamento; oferecer alternativas de resposta; dar sugestão de opostos; categorização; mudança de conjunto aberto para intermediário ou para fechado quando necessário; aproximação da criança; estratégias de comunicação com a criança; prolongamento; técnica do sanduíche auditivo; fechamento auditivo; sussurro; fechar os olhos e sabotagem auditiva (BEVILACQUA; FORMIGONI, 2012; GRANHA, 2008; RESEGUE-COPPI, 2008).

Com a necessidade de investimento em formação de fonoaudiólogos especializados em (re)habilitação auditiva, o uso da ferramenta da Telessaúde, neste caso, a teleconsultoria, pode viabilizar a formação em serviço e a melhoria da qualidade dos atendimentos prestados aos usuários dos serviços de saúde brasileiro, vinculados ao Sistema Único de Saúde.

Ao utilizar as novas tecnologias em saúde é possível superar as barreiras físicas e geográficas, tornando a tecnologia da comunicação uma ferramenta fundamental e indispensável para formação, atualização e prática profissional no campo da saúde. Em um país com grande extensão territorial, como é o caso do Brasil, a utilização dos meios tecnológicos de comunicação pode suavizar as desigualdades observadas entre regiões do país (FONSÊCA; BRAZOROTTO; BALEN, 2015; MOLINA-ALVEJONAS, 2015; SPINARDI; HERRERA; MAXIMINO, 2013). Assim, em nosso país, as ações de implementação da Telefonoaudiologia são discutidas para o fortalecimento dos serviços fonoaudiológicos em diferentes níveis de atenção (BARBOZA DO NASCIMENTO et al., 2017).

A utilização dos recursos de telessaúde para os serviços de reabilitação em Audiologia tem demonstrado grandes avanços. Algumas das questões importantes a serem solucionadas para capitalizar ainda mais o potencial destas ferramentas são as limitações da internet de banda larga nas regiões remotas e o custo-efetividade dos serviços oferecidos (BUSH et al., 2016).

As atitudes positivas dos profissionais em relação ao uso das ferramentas da Telessaúde em Audiologia foram constatadas pelo estudo de revisão sistemática conduzido por Ravi et al. (2018), que também destacou os principais desafios referentes à limitação de infraestrutura, licença para a realização destes serviços e o reembolso, no caso de teleaudiologia aplicada aos pacientes.

Evidências atuais indicam que o uso da telessaúde é um modelo efetivo também para a oferta de serviços às famílias de crianças com deficiência auditiva. (MCCARTHY et al., 2018). A teleconsultoria, como estratégia de educação profissional em Fonoaudiologia, pode, inclusive, capacitar os fonoaudiólogos para atuarem com as ferramentas tecnológicas necessárias para 
a prestação de serviços aos pacientes na modalidade à distância.

A teleconsultoria é, pois, uma consulta registrada e realizada entre trabalhadores, profissionais e gestores da área de saúde, por intermédio de instrumentos de telecomunicação bidirecional, cuja finalidade é esclarecer dúvidas sobre procedimentos clínicos, ações de saúde e questões relativas ao processo de trabalho, podendo essa consultoria a distância ser exercida de duas formas: síncrona, ou seja, realizada em tempo real por meio de chat, web e videoconferência, ou assíncrona, a qual é realizada por meio de mensagem off-line, ambas com intuito de esclarecer dúvidas e orientar a respeito de procedimentos clínicos e terapêuticos entre profissionais da saúde (BRASIL, 2012).

De acordo com a Resolução do CFFa $n^{\circ}$ 427, de $1^{\circ}$ de março de 2013, Art. $1^{\circ}$, define-se a Telessaúde em Fonoaudiologia: "como exercício da profissão por meio das tecnologias de informação e comunicação com a utilização de metodologias interativas e de ambientes virtuais de aprendizagem com as quais poder-se-á assistência, promover educação e a realização de pesquisa em saúde" (CONSELHO FEDERAL DE FONOAUDIOLOGIA, 2013).

Com base na necessidade de se estudar a aplicação da teleconsultoria em terapia fonoaudiológica especializada em (re) habilitação auditiva, o estudo de Xavier (2014), avaliou o uso da teleconsultoria síncrona, demonstrando que esse tipo de teleconsutoria produziu efeito positivo nas terapias fonoaudiológicas de bebês e crianças com deficiência auditiva, bem como uma melhoria na formação em serviço dos profissionais da Fonoaudiologia participantes da pesquisa.

Ribeiro (2015) deu continuidade ao trabaIho de Xavier (2014), e segundo o seu estudo, a teleconsultoria síncrona produziu evolução na qualidade das terapias das fonoaudiólogas que atuam no atendimento de crianças com deficiência auditiva. Apesar do pouco tempo de intervenção, foi evidenciada melhora, uma vez que o modelo aplicado demonstrou indícios de efetividade para a melhoria da qualidade da intervenção fonoaudiológica (RIBEIRO, 2015).

Na pesquisa de Marcolino et al. (2014) foram estudadas a utilização, efetividade e resolutividade das teleconsultorias realizadas pela Rede de Teleassistência de Minas Gerais. Neste estudo, o modelo usado foi o de teleconsultoria assíncrona, com diversas especialidades da saúde. Os autores concluíram que o modelo assíncrono foi capaz de quebrar barreiras físicas e no acesso à assistência, ajudando na eficiência de uma educação permanente (MARCOLINO et al., 2014).

A satisfação dos usuários com um sistema de teleconsultoria assíncrono foi avaliada por Gismond e colaboradores (2017), indicando que $82,4 \%$ dos profissionais relataram que mudaram a abordagem do problema. Os autores concluíram que o sistema implantado contribui para melhorar as condutas clínicas. À vista disso, embora o uso da teleconsultoria em Fonoaudiologia seja ainda incipiente, observa-se o grande potencial de utilização deste instrumento na prática clínica. (LUCENA et al., 2016). Neste sentido, os objetivos deste estudo de caso são: avaliar o efeito da teleconsultoria assíncrona sobre a qualidade da terapia fonoaudiológica de crianças com deficiência auditiva, bem como analisar a satisfação dos fonoaudiólogos com a teleconsultoria no modelo assíncrono.

\section{MATERIAIS E MÉTODOS}

Trata-se de uma pesquisa de delineamento longitudinal, por meio de estudo de caso sob intervenção, com análise qualitativa dos dados.

Esse estudo foi realizado no Centro de Saúde Auditiva SUVAG RN e no Departamento de Fonoaudiologia da Universidade Federal do Rio Grande do Norte (UFRN), em Natal/RN. As 
teleconsultorias foram realizadas em diferentes ambientes, incluindo a casa dos pesquisadores, devido à necessidade de acesso à internet para a conectividade durante a teleconsultoria assíncrona.

O presente trabalho é parte de um estudo amplo, denominado: Estudos clínicos sobre o desenvolvimento de crianças com deficiência auditiva: subsídios para a melhoria de sua (re)habilitação, aprovado pelo CEP com parecer de número 1.144.295 (ANEXO A).

Tanto os familiares responsáveis pelas crianças, quanto seus fonoaudiólogos foram convidados a participar e assinar o termo de consentimento livre e esclarecido TCLE (APÊNDICE C).
Foi realizado o convite aos fonoaudiólogos que trabalhavam em Prefeituras do Estado do Rio Grande do Norte, bem como nos Serviços de Saúde Auditiva de alta complexidade, credenciados ao Sistema Único de Saúde. Duas Fonoaudiólogas, chamadas no presente estudo de F1 e F2, se disponibilizaram a participar da pesquisa.

Os critérios de inclusão foram: fonoaudiólogos que estivessem no momento da pesquisa acompanhando o processo terapêutico de bebês e/ou crianças com deficiência auditiva e que possuíssem computadores com acesso à internet no local de trabalho.

Na Tabela 1, verifica-se a caracterização dos fonoaudiólogos participantes:

\begin{tabular}{|c|c|c|c|c|}
\hline Idade (anos) & $\begin{array}{c}\text { Tempo de formado } \\
\text { em Fonoaudiologia }\end{array}$ & $\begin{array}{c}\text { Especialização em } \\
\text { Audiologia }\end{array}$ & $\begin{array}{c}\text { Tempo de experiência } \\
\text { no atendimento } \\
\text { às pessoas com } \\
\text { deficiência auditiva }\end{array}$ \\
\hline F1 & 29 & $1 \mathrm{a}$ e $10 \mathrm{~m}$ & Não & $1 \mathrm{a}$ \\
\hline F2 & 23 & $1 \mathrm{a}$ e $10 \mathrm{~m}$ & Não & $7 \mathrm{~m}$ \\
\hline
\end{tabular}

Tabela 1 - Caracterização dos fonoaudiólogos participantes.

Fonte: Autoria própria (2018).

Em relação às crianças atendidas, foram 3 crianças com deficiência auditiva (duas atendidas pela fonoaudióloga F1, chamadas de $\mathrm{C} 1$ e $\mathrm{C} 2$ e uma atendida pela fonoaudióloga F2, a criança C3). A caracterização das crianças participantes, atendidas pelas fonoaudiólogas, está apresentada na Tabela 2, a seguir: 


\begin{tabular}{|c|c|c|c|c|c|}
\hline Identificação & Idade & Tipo/grau da DA & DEAA & $\begin{array}{c}\text { Uso efetivo de } \\
\text { AASI }\end{array}$ & $\begin{array}{c}\mathrm{N}^{\circ} \\
\text { terapias/ } \\
\text { semana }\end{array}$ \\
\hline C1 & $2 \mathrm{a} 7 \mathrm{~m}$ & SNPB & $\begin{array}{c}\text { AASI } \\
\text { Bilateral }\end{array}$ & Sim & 2 \\
\hline C2 & 2a $5 m$ & $\begin{array}{l}\text { SNS OD } \\
\text { SNL OE }\end{array}$ & $\begin{array}{l}\text { AASI Unilateral } \\
\text { (OD) }\end{array}$ & Sim & 2 \\
\hline $\mathrm{C} 3$ & 11a $3 \mathrm{~m}$ & $\begin{array}{l}\text { CL OD } \\
\text { MS OE }\end{array}$ & $\begin{array}{c}\text { AASI Unilateral } \\
(\mathrm{OE})\end{array}$ & Sim & 2 \\
\hline \multicolumn{6}{|c|}{$\begin{array}{l}\text { Nota: DA - Deficiência Auditiva; DEAA - Dispositivo Eletrônico Auxiliar à Audição; AASI - Aparelho de Amplificaçã } \\
\text { Sonora Individual; SNPB - Perda Auditiva Sensorioneural de Grau Profundo Bilateralmente; SNSOD- Perda auditiv } \\
\text { Sensorioneural de Grau Severo na Orelha Direita; SNLOE- Perda auditiva de Grau Leve na Orelha esquerda; } \\
\text { OD-Orelha direita; OE-Orelha esquerda; CLOD-Condutiva de Grau leve na orelha direita; MSOE- Mista de Grau } \\
\text { Severo na Orelha Esquerda. }\end{array}$} \\
\hline
\end{tabular}

Tabela 2 - Caracterização das crianças atendidas pelos fonoaudiólogos.

Fonte: Autoria própria (2018).

Dentre os materiais e equipamentos necessários para que a pesquisa fosse desenvolvida, foi utilizado um computador com conexão internet wireless banda larga, um espaço virtual para o armazenamento dos vídeos de terapia (Google Drive), um e-mail (Gmail) para encaminhar as devolutivas das análises das sessões terapêuticas de $\mathrm{F} 1$ e F2, além de materiais rotineiros como folhas de registro das análises dos vídeos, lápis, borracha, caneta e tinta de impressora.

$O$ instrumento utilizado para proceder a análise das sessões de terapia fonoaudiológica foi adaptado e utilizado em dois estudos anteriores sobre a teleconsultoria síncrona (XAVIER, 2014; RIBEIRO, 2015). Tal instrumento é composto por requisitos das técnicas e estratégias de comunicação, que devem ser empregadas pelo fonoaudiólogo na terapia com a criança com deficiência auditiva. A análise conta com uma escala de Likert, na qual os comportamentos raramente observados são pontuados como 1, 2 ou 3, os comportamentos ocasionalmente observados (50\% do tempo) são pontuados como 4, e os comportamentos frequentemente observados são pontuados respectivamente como 5,6 ou 7 . No instrumento também consta um espaço para observações de análises mais específicas de trechos da sessão que se queira destacar durante a teleconsultoria com o fonoaudiólogo.

A coleta de dados foi realizada nas seguintes etapas: registro digital da sessão terapêutica; elaboração do conteúdo a ser abordado na teleconsultoria; realização da teleconsultoria assíncrona, sendo a mesma realizada em até 72 horas após o registro em vídeo encaminhado pelos fonoaudiólogos participantes da pesquisa.

Os fonoaudiólogos F1 e F2 registraram trechos entre 5 a 10 minutos de momentos da terapia com crianças com deficiência auditiva, e encaminharam ao pesquisador (teleconsultor) que os orientou sobre as técnicas e os procedimentos mais apropriados e específicos sobre os casos analisados. Também foi solicitado aos participantes que preenchessem uma avaliação da Satisfação 
com a Teleconsultoria em Audiologia Educacional, após o término das cinco teleconsultorias realizadas.

Em relação ao agendamento das teleconsultorias assíncronas, os fonoaudiólogos foram orientados sobre as disponibilidades de horário dos pesquisadores, os quais ficaram à disposição nos momentos em que achassem necessário a realização da teleconsultoria. Foi encaminhada, aos fonoaudiólogos, uma cópia dos instrumentos de análise da avaliação da teleconsultoria em Audiologia educacional e o instrumento da avaliação da sessão terapêutica. Também foram encaminhados a esses profissionais materiais de estudo em português sobre a terapia fonoaudiológica com crianças com deficiência auditiva, bem como sugestões de estratégias terapêuticas com materiais para aplicação, se desejável, com as crianças com deficiência auditiva atendidas por eles.

O critério de confiabilidade entre os julgadores dos vídeos foi estabelecido para que em todos os itens do instrumento de análise da sessão terapêutica, a pontuação de determinados itens não tivesse mais do que 1 ponto de diferença, e que estivessem sempre dentro da mesma categoria (ex: pontos 5, 6 ou 7 referem-se a comportamentos frequentemente observados na terapia).

A tabulação dos dados (análise independente dos avaliadores de cada vídeo de interação pré e pós teleconsultorias) foi seguida pela análise estatística inferencial dos dados no Software $\mathrm{R}$, por meio do Método JT, proposto inicialmente no âmbito da Psicologia Clínica para a investigação da efetividade de intervenções. Descrito por Jacobson, Truax (1991), particularmente voltado para a análise da significância clínica dos resultados obtidos com uma intervenção, ainda que não seja possível aplicar o tratamento em um grande número de sujeitos.

O Método JT prevê uma análise comparativa entre escores pré e pós-intervenção com o objetivo de estabelecer se as distinções entre eles representam mudanças confiáveis e se são relevantes clinicamente. Tal método se articula em dois conceitos básicos: a significância clínica, mais voltada para a validade externa (produção de mudanças efetivas do ponto de vista do participante, do clínico ou da família na intervenção) e o índice de mudança confiável, relacionado à validade interna (fator que determina se as mudanças observadas na comparação entre a pré e a pós-intervenção podem ser relacionadas aos procedimentos de intervenção utilizados ou à erros de medida).

Desta forma, foi possível afirmar se as mudanças (ocorridas ou não) foram decorrentes da intervenção realizada (teleconsultorias) para cada uma das fonoaudiólogas.

\section{RESULTADOS}

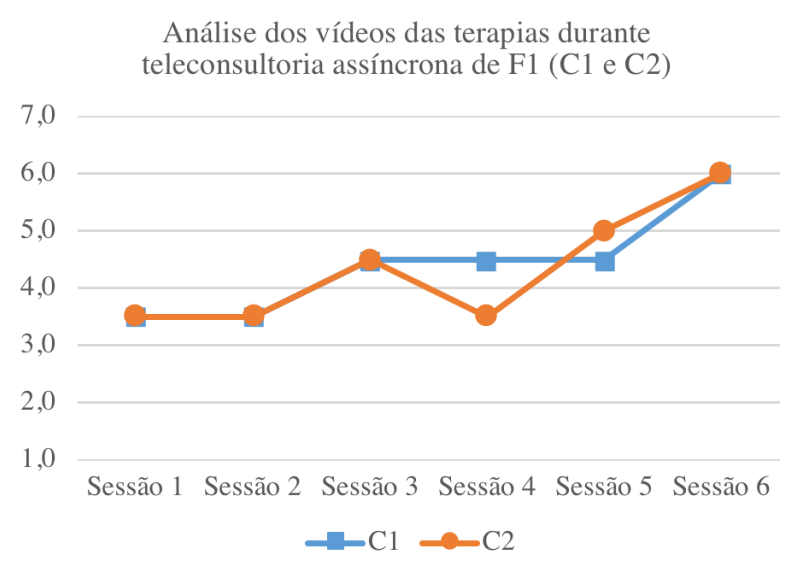

Figura 1 - Escores obtidos a partir do IATE para a fonoaudióloga F1.

Fonte: Autoria própria (2018).

Na figura 1, apresenta-se a mediana dos escores obtidos em cada sessão de terapia de F1. Foi possível observar uma melhora da conduta de F1 em suas sessões terapêuticas a partir da terceira sessão. Foram realizadas cinco teleconsultorias com $\mathrm{F} 1$, a partir da analises dos vídeos das sessões de terapia com a criança C1 e a criança C2.mais resistentes a agentes antimicrobianos (UTTER; WELCH; BORISY, 2016; COLOMBO; MATAFORA; MORO, 2014; PORCIUNCULA et al., 2015). 
Análise dos vídeos das terapias durante teleconsultoria assíncrona de F2 (C3)

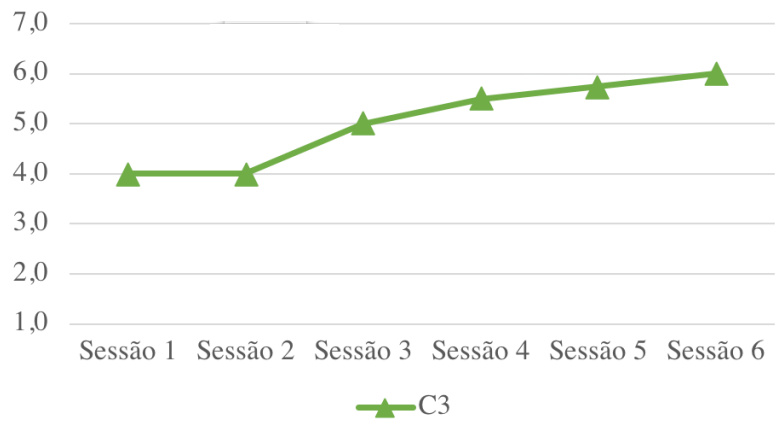

Figura 2 - Escores obtidos a partir do IATE para a fonoaudióloga F2.

Fonte: Autoria própria (2018).

$\mathrm{Na}$ figura 2, observa-se uma melhora da conduta terapêutica a partir da terceira sessão de terapia do fonoaudiólogo F2, considerando a mediana de avaliação de todas as sessões de terapia para os itens do instrumento de análise da sessão terapêutica. F2 teve cinco teleconsultorias, por meio das análises dos vídeos das sessões de terapia com a criança C3.

De acordo com os itens de análise do instrumento proposto para as teleconsultorias, os aspectos da sessão terapêutica que foram aprimorados pelas fonoaudiólogas F1 e F2 foram: o terapeuta segue o interesse da criança na maioria das vezes; o terapeuta envolve a criança na atividade; o terapeuta fala sobre o que a criança está fazendo ou olhando; o terapeuta usa adequadamente a fala, movimentos, toques e/ou gestos para chamar a atenção da criança para objetos e acontecimentos, todos envolvendo sensibilidade e atenção à criança.

No subitem coerência e integração entre metas e estratégias, o aspecto no qual foi notada melhora para ambas as fonoaudiólogas foi: o terapeuta focaliza a terapia no desenvolvimento da linguagem por meio da audição. No subitem qualidade das atividades e materiais, foram observadas mudanças nos seguintes aspectos: o terapeuta explora e balanceia o uso do caderno de experiências, literatura infantil, músicas, jogos, na terapia, as estratégias chamam a atenção da criança e ainda os materiais e brincadeiras são apropriados à faixa etária e desenvolvimento da criança.

No subitem técnicas terapêuticas, foi possível notar mudança positiva para o fonoaudiólogo F1 quanto aos aspectos: o terapeuta incorpora músicas às estratégias e canta durante as atividades terapêuticas e o terapeuta usa padrões apropriados de voz e fala (aspectos suprassegmentais e velocidade, em especial).

Quanto ao subitem família o terapeuta comunica-se de maneira positiva e tem efetiva interação com a família e o terapeuta facilita a participação da família na terapia? Foi notada melhora da F1, já a F2 não teve oportunidade de trabalhar com a família da paciente atendida. Para o fonoaudiólogo F2, no subitem técnicas terapêuticas, foi observada melhora quanto aos itens: checagem auditiva com os Sons de Ling; trabalho com a memória auditiva; utilização das técnicas terapêuticas (sabotagem, sanduíche auditivo, sussurro, fechar os olhos, fechamento auditivo, destaques acústicos); uso do conjunto intermediário e aberto para o treinamento auditivo, com especial destaque para o emprego das técnicas de sussurro, fechamento auditivo, sabotagem auditiva e técnica de pedir para a criança fechar os olhos, otimizando, assim, o trabalho com as habilidades auditivas.

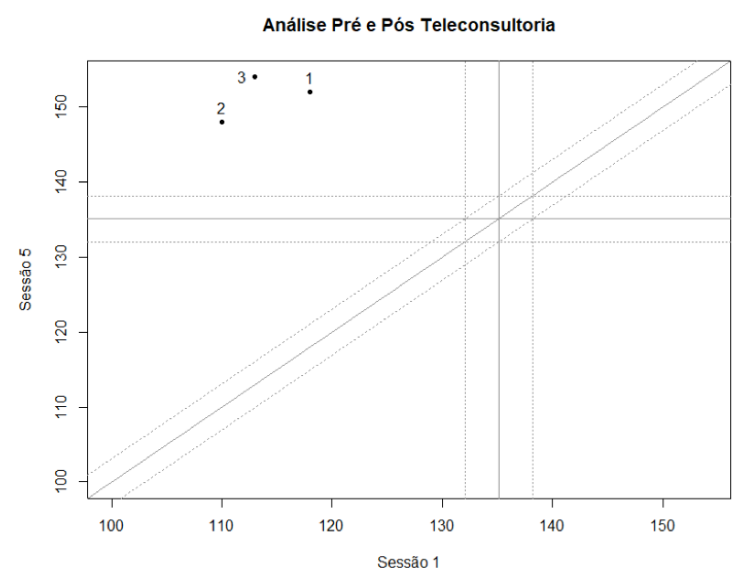

Obs: alpha de 0.9

Figura 3 - Índice de Mudança Confiável da Terapia Fonoaudiológica Pré e Pós Teleconsultorias.

Fonte: Autoria própria (2018). 
Na comparação da primeira e da última avaliação realizadas na ocasião das sessões de teleconsultoria, observou-se que ambos os fonoaudiólogos (F1 - atendimentos dos casos 1 e 2 e F2 - atendimento do caso 3) obtiveram índice de mudança confiável, comprovando, assim, a efetividade das teleconsultorias realizadas para a melhoria da qualidade das terapias fonoaudiológicas às crianças com deficiência auditiva.

No quadro 1, apresenta-se a análise qualitativa das sessões e as recomendações das teleconsultorias realizadas com F1 e F2.

\begin{tabular}{|c|c|c|c|c|c|}
\hline Sujeitos & Teleconsultoria 1 & Teleconsultoria 2 & Teleconsultoria 3 & Teleconsultoria 4 & Teleconsultoria 5 \\
\hline F1 & 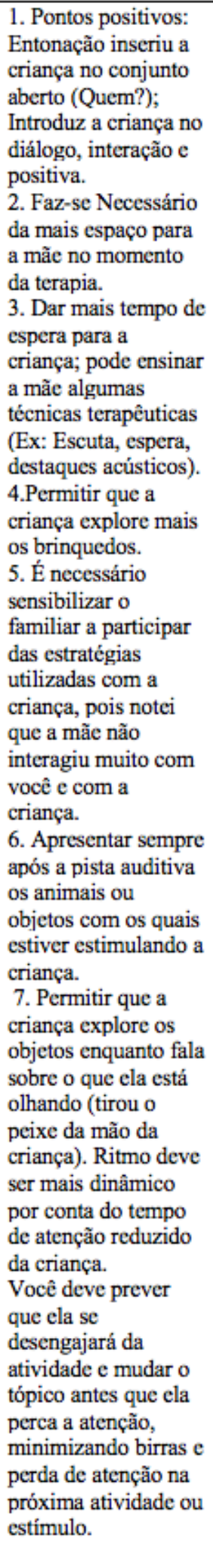 & 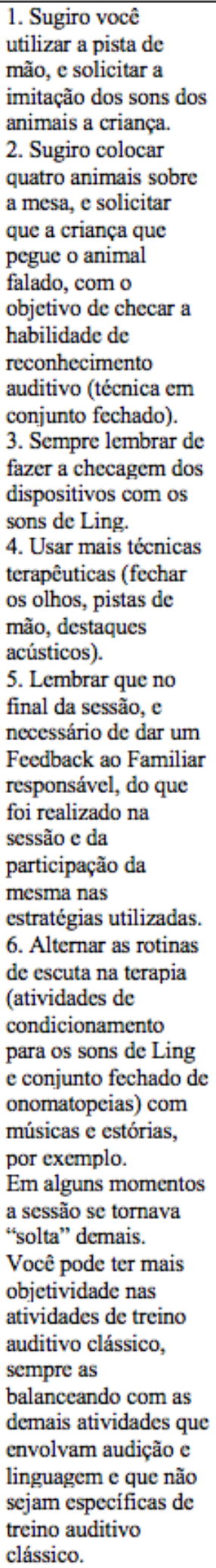 & 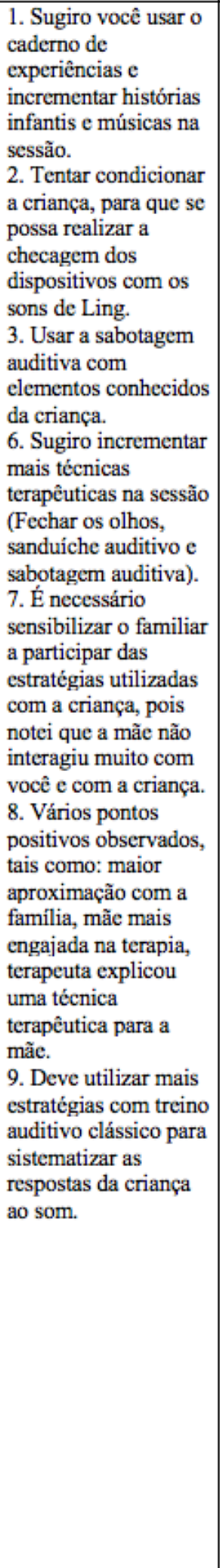 & 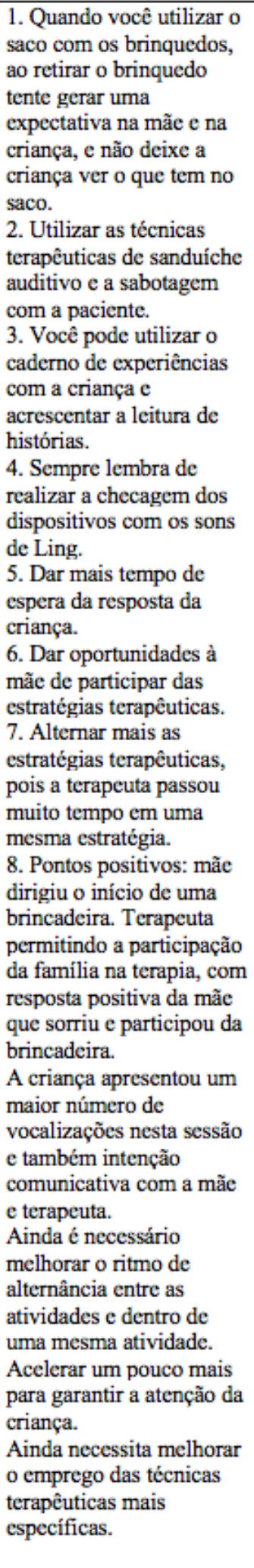 & $\begin{array}{l}\text { 1. Na estratégia com } \\
\text { o cubo, também e } \\
\text { possível estimular as } \\
\text { cores. } \\
\text { 2. Seria importante } \\
\text { você utilizar o } \\
\text { caderno de } \\
\text { experiência com a } \\
\text { criança. } \\
\text { 3. Você pode utilizar } \\
\text { a técnica terapêutica } \\
\text { do sussurro com a } \\
\text { criança. } \\
\text { 4. Faz-se necessário } \\
\text { lembrar que no final } \\
\text { da terapia é } \\
\text { necessário dar } \\
\text { feedback da } \\
\text { participação da } \\
\text { familia. } \\
5 \text {. Usar livros infantis } \\
\text { com a criança. } \\
6 \text {. Pontos positivos } \\
\text { observados: Uso de } \\
\text { destaque acústico de } \\
\text { aproximação do } \\
\text { dispositivo, técnica } \\
\text { de escuta, chamar e } \\
\text { se despedir dos } \\
\text { brinquedos, que foi } \\
\text { usada em todas as } \\
\text { sessões, Imitação e } \\
\text { fechamento auditivo. } \\
\text { Mãe mais à vontade } \\
\text { na sessão (fez } \\
\text { comentário sobre o } \\
\text { gato. Antes ficava } \\
\text { calada a sessão toda). } \\
\text { Um sinal de que você } \\
\text { permitiu que ela } \\
\text { passe. }\end{array}$ \\
\hline
\end{tabular}




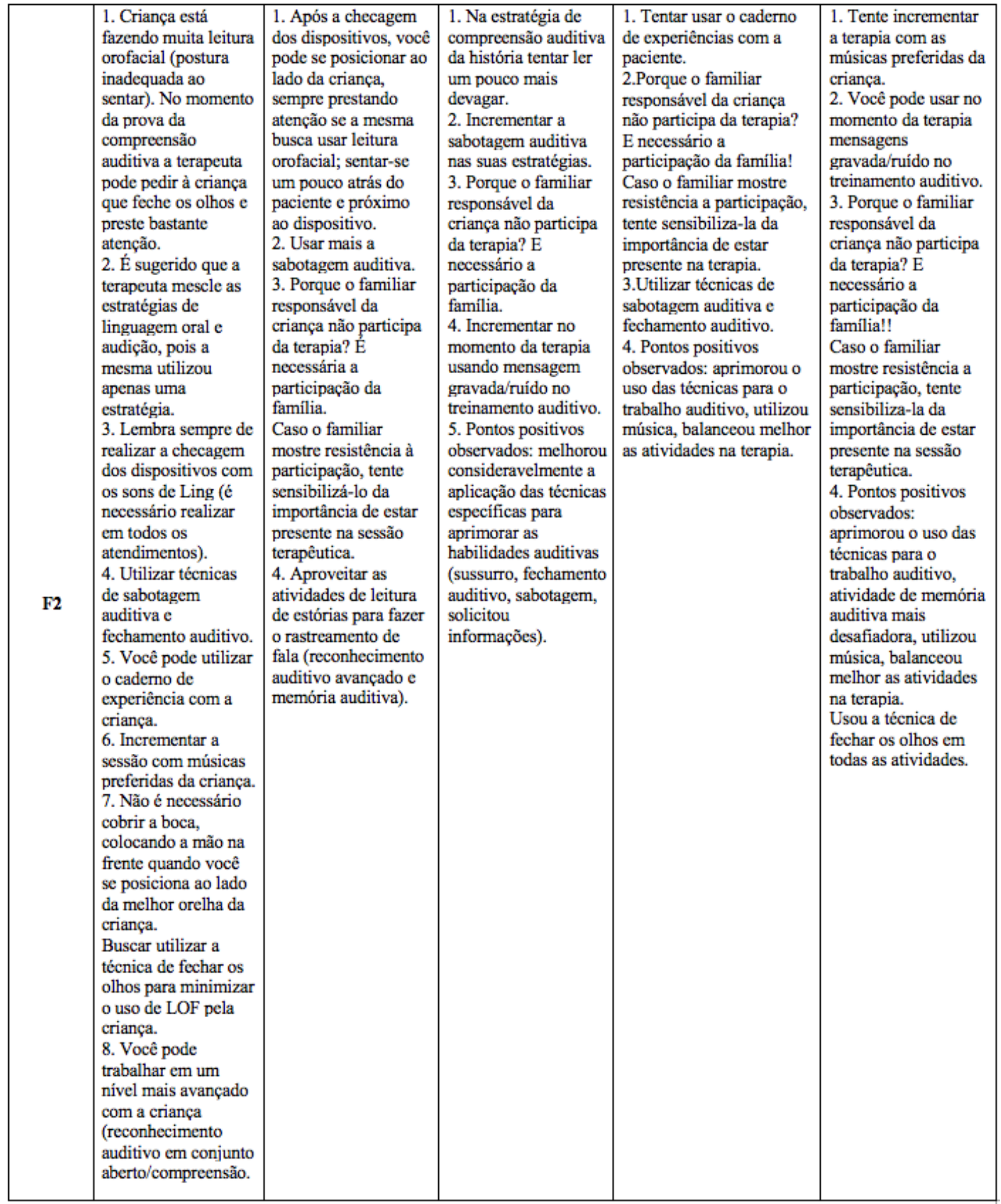

Quadro 1 - Análise qualitativa das sessões e as recomendações das teleconsultorias realizadas. 
Na Figura 4, apresenta-se a avaliação da satisfação dos fonoaudiólogos com a teleconsultoria assíncrona.

\section{Avaliação da Satisfação com a Teleconsultoria}

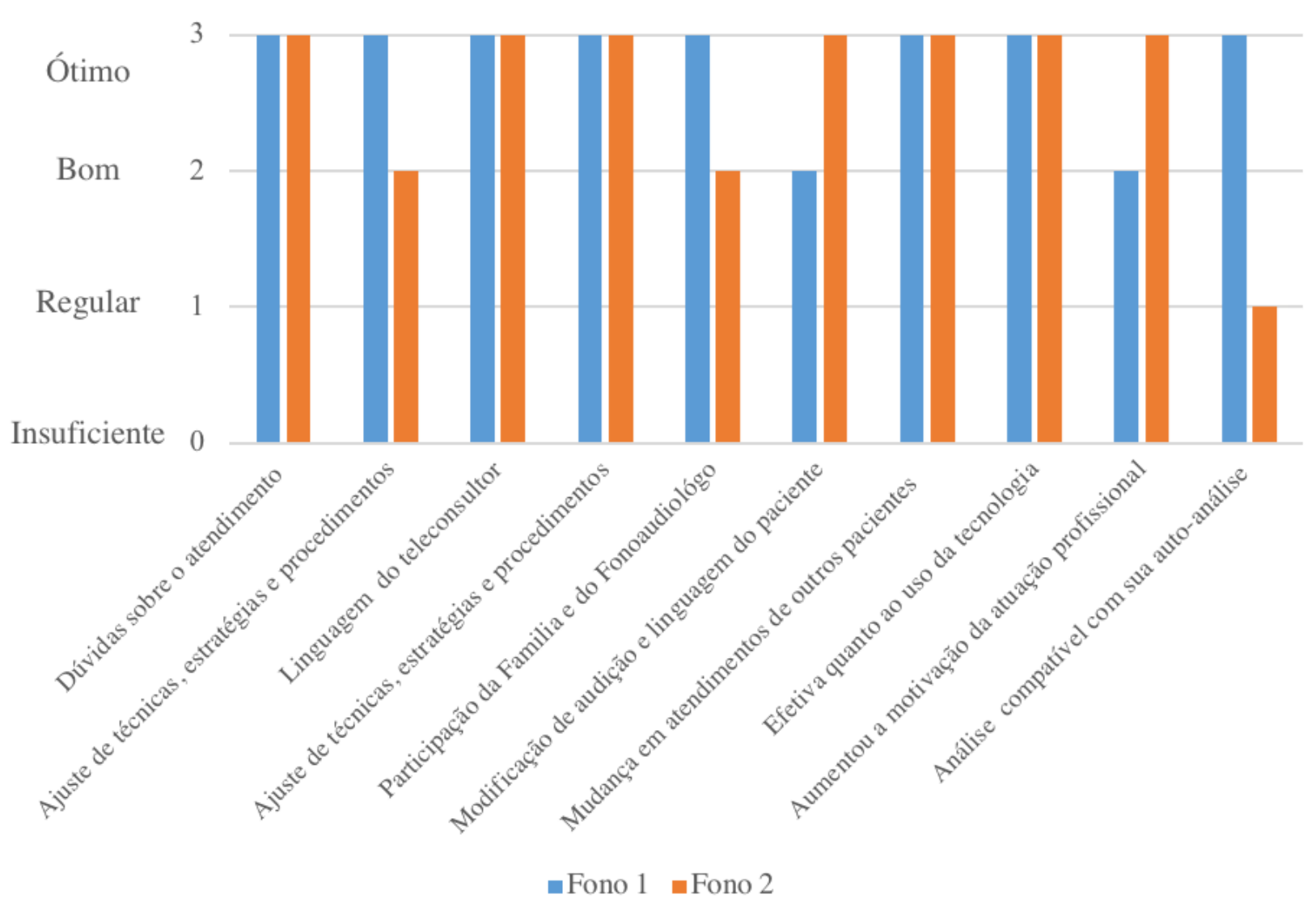

Figura 4 - Análise da satisfação dos fonoaudiólogos com a teleconsultoria assíncrona.

Fonte: Autoria própria (2018).

Quanto à análise da satisfação dos fonoaudiólogos com a teleconsultoria assíncrona, a partir do questionário respondido por F1 e F2 participantes da pesquisa, foi observado na Figura 3 que a maioria dos itens obteve a pontuação máxima, evidenciando a satisfação dos fonoaudiólogos com a teleconsultoria assíncrona.

Os itens de pontuação máxima quanto à satisfação com a teleconsultoria assíncrona foram: a teleconsultoria respondeu às dúvidas sobre o atendimento; a linguagem do teleconsultor foi adequada para a boa compreensão do conteúdo; na teleconsultoria foram explicitadas evidências científicas para o ajuste de técnicas, estratégias e procedimentos; a teleconsultoria realizada com os pacientes auxiliou na mudança em atendimentos de outros pacientes e a teleconsultoria foi efetiva quanto ao uso da tecnologia.

Observaram-se aspectos que podem ser aprimorados para futuras pesquisas e para o uso da teleconsultoria como uma ferramenta de melhoria da qualidade dos serviços na área de terapia fonoaudiológica, a saber:

- A necessidade de uma base de dados virtual eficiente e segura para o armazenamento dos vídeos de terapia, o que foi feito por meio do recurso Google Drive, contudo, com espaço limitado, fato que causou demora no descarregamento de vídeos maiores; 
- Apesar de terem sido orientados quanto ao descarregamento dos vídeos, os fonoaudiólogos tiveram dificuldade nesta etapa, sendo necessária a capacitação dos fonoaudiólogos quanto ao uso destes recursos previamente à execução de teleconsultorias;

- A Conectividade da internet de baixa qualidade para o serviço de saúde auditiva interferiu negativamente no envio dos vídeos ao teleconsultor via base de dados (Google Drive). De modo que este é um aspecto importante a se considerar na participação de fonoaudiólogos em pesquisas e na efetivação da teleconsultoria para municípios em que a velocidade de internet é de baixa qualidade;

- A disponibilidade dos fonoaudiólogos F1 e F2 foi favorável à execução desta pesquisa. No entanto, outros fonoaudiólogos do serviço não se envolveram, sendo esta uma questão de gestão de recursos humanos importante na aplicação da teleconsultoria em serviços de saúde auditiva;

- O treinamento de uma equipe de teleconsultores se faz necessário, dada a especificidade das análises de qualidade que devem ser realizadas na terapia fonoaudiológica Aurioral.

\section{DISCUSSÃO}

De acordo com os resultados, observou-se uma modificação positiva na aplicação de técnicas terapêuticas pelos fonoaudiólogos F1 e F2, demonstrando os efeitos da teleconsultoria assíncrona na melhoria da qualidade da terapia fonoaudiológica com crianças com deficiência auditiva, corroborando os dados de duas pesquisas realizadas por meio da teleconsultoria no modelo síncrono. (XAVIER, 2014, RIBEIRO, 2015). Destaca-se, no entanto, que para as teleconsultorias síncronas, o efeito positivo nas terapias ocorreu a partir da primeira teleconsultoria, demonstrando ter sido mais rápido do que o observado na aplicação da teleconsultoria assíncrona, na qual notou-se mudanças positivas após a terceira sessão de teleconsultoria.

Em contraposição, a viabilidade para a participação dos fonoaudiólogos na teleconsultoria assíncrona foi maior do que a notada em estudos anteriores com o modelo síncrono, devido ao tempo dos fonoaudiólogos para agendar a teleconsultoria síncrona, sendo esta uma vantagem da assincronicidade da teleconsultoria em saúde, ou seja, o profissional pode eleger o melhor momento para a análise de seu processo de trabalho (MARCOLINO et al., 2014; LUCENA, 2016).

Sobre os aspectos examinados a partir do instrumento de análise da sessão terapêutica, foi possível observar que a participação da família ainda não é parte da rotina do serviço com todas as crianças, o que foi evidenciado pela falta da família em todas as seis sessões analisadas do fonoaudiólogo F2, fato que é preocupante quanto ao prognóstico de alta fonoaudiológica, e constatou-se também em estudos anteriores (XAVIER, 2014; RIBEIRO, 2015).

Destaca-se a importância do envolvimento familiar como um fator robusto para resultados na habilitação e reabilitação auditiva (BEVILACQUA; FORMIGONI, 2012). Um ponto importante quanto a este item, foi a pouca participação das famílias das crianças C1 e C2 nas estratégias terapêuticas das sessões, especialmente no início da intervenção por meio da teleconsultoria, aspecto que foi aprimorado pelo fonoaudiólogo F1 após as teleconsultorias.

A família deve, portanto, ser protagonista do processo de (re)habilitação de seus filhos, sendo importante que o fonoaudiólogo considere a participação da família na sessão como uma possibilidade de treino de habilidades para empoderá-las a dar o suporte necessário ao desenvolvimento 
das habilidades de audição e de linguagem de seus filhos. (CRUZ et al., 2013).

No Brasil, a Abordagem Aurioral destaca-se como um conjunto de estratégias, técnicas e procedimentos sistematizados para o trabalho de audição e linguagem em crianças com deficiência auditiva (BEVILACQUA; FORMIGONI, 2012). De fato, esta abordagem tem como premissa priorizar a audição da criança para que ela aprenda a ouvir e, assim, expanda os conhecimentos, experiências de vida e se integre participando ativamente do meio que a cerca, já que a audição é importante para o desenvolvimento da comunicação oral e das trocas interpessoais (RESEGUECOPPI, 2008). No caso da fonoaudióloga F1, que teve uma formação de base sobre a Abordagem Aurioral, foi mais natural utilizar a via auditiva para a construção da linguagem das crianças por ela atendidas. No caso da fonoaudióloga F2, nas primeiras sessões de terapia analisadas, notou-se uso excessivo de leitura orofacial, mesmo quando a criança não solicitava pistas visuais. Este fato foi atribuído durante a análise das primeiras sessões, à formação de F2, que não foi específica sobre a terapia Aurioral. Destaca-se que, após três sessões de teleconsultoria, foi observada melhora notória no uso da pista auditiva para o desenvolvimento das estratégias terapêuticas com a C3.

Em relação à verificação dos AASls utilizando os sons de Ling ([a], [i], [u], [m], [s] e [x]), F1 e F2 não realizavam a checagem dos DEAA rotineiramente, visto que nos primeiros minutos de terapia não era possível observar nos vídeos a execução deste procedimento. Foi questionado às fonoaudiólogas se elas realizavam esta checagem e ambas informaram que faziam, não necessariamente nos primeiros momentos da terapia. $\bigcirc$ pesquisador sugeriu que o procedimento fosse incorporado à rotina inicial da terapia, dada a importância desta verificação, pois esses sons abrangem as frequências graves, médias e agudas, possibilitando avaliar se a criança está percebendo todos os sons e se seus equipamentos eletrônicos estão em perfeito funcionamento. A recomendação é que esse teste seja realizado em todas as sessões terapêuticas (RESEGUE-COPPI, 2008).

O uso das técnicas terapêuticas foi o outro item abordado nas teleconsutorias de F1 e F2, observando-se que após a instrução específica do teleconsultor sobre a aplicação destas técnicas, os fonoaudiólogos incorporaram as mesmas às sessões de terapia. As técnicas mais utilizadas pelas terapeutas foram: sabotagem auditiva, sanduíche auditivo, sussurro, fechar os olhos, fechamento auditivo, destaques acústicos, uso do conjunto intermediário e aberto para o treinamento auditivo e técnica de pedir para a criança fechar os olhos. Tais técnicas são descritas por diversos autores como fundamentais para auxiliarem a criança no processo de reabilitação auditiva, otimizando assim, o trabalho com as habilidades auditivas. (BEVILACQUA; FORMIGONI, 2012; GRANHA, 2008; RESEGUE-COPPI, 2008).

$\mathrm{Na}$ avaliação de satisfação no período pós teleconsultoria realizada pelos fonoaudiólogos F1 e F2, participantes do presente estudo evidenciaram que as teleconsultorias assíncronas contribuíram para o aprimoramento da terapia fonoaudiológica em crianças com deficiência auditiva. Os fonoaudiólogos F1 e F2 atribuíram a pontuação máxima na maioria dos itens do questionário de satisfação (APÊNDICE B), demonstrando-se satisfeitos com este modelo de teleconsultoria, assim como o concluído por Xavier (2014), com relação ao modelo síncrono.

O modelo de teleconsultoria assíncrona mostrou-se objetivo, pois deu aos fonoaudiólogos suporte para que utilizassem as orientações propostas pelos avaliadores na sessão de terapia subsequente à teleconsultoria, especialmente após a terceira sessão, o que corrobora achados da literatura sobre este modelo de teleconsultoria em várias especialidades em saúde (GISMOND et al., 2017; LUCENA et al., 2016; MARCOLINO et al., 2014). 
Uma das principais dificuldades encontradas no uso da teleconsultoria neste estudo foi a conectividade da internet do serviço de saúde auditiva, que interferiu negativamente para o envio dos vídeos aos teleconsultores via base de dados (Google Drive), sendo este um aspecto importante a se considerar para a participação de fonoaudiólogos em pesquisas e na efetivação da teleconsultoria nos municípios em que a velocidade de internet é de baixa qualidade. Para Correia et al (2014) a telessaúde na região norte/nordeste apresenta um grande desafio quanto à qualidade da conectividade, desafio também apontado pelo estudo de revisão sistemática de Molina-Alvejonas, et al. (2015) e outros autores. (RAVI et al., 2018; BUSH et al., 2016).

Houve crescimento notório nos últimos anos de Telessaúde em Fonoaudiologia, mas ainda há necessidade de ser ampliada no Brasil, o que favorecerá a ciência e a oferta de serviços fonoaudiológicos de reabilitação e habilitação às populações que ainda carecem deste acesso (FONSÊCA; BRAZOROTTO; BALEN, 2015; BARBOZA DO NASCIMENTO et al., 2017 ; LEITÃO et al., 2018), sendo esta uma das conclusões do presente estudo, ao constatar a melhoria na qualidade das terapias Fonoaudiológicas de F1 e F2, corroborando com a afirmação sobre a necessidade do uso dos recursos da telessaúde na prática fonoaudiológica.

A teleconsultoria possibilitou aos profissionais inseridos no Serviço de Saúde Auditiva, um desenvolvimento contínuo por meio da análise de seu processo de trabalho, permitindo ao fonoaudiólogo que aplique prontamente os conhecimentos adquiridos em sua atuação prática, culminando em melhoria na qualidade do serviço de terapia fonoaudiológica ofertado aos usuários, fato destacado na literatura sobre a necessidade dos fonoaudiólogos se adaptarem ao uso das ferramentas da telessaúde para o cuidado em saúde (MOLINA-ALVEJONAS et al., 2015, MCCARTHY et al., 2018).

\section{CONCLUSÃO}

A teleconsultoria assíncrona, uma importante ferramenta da telessaúde destacada pela literatura, produziu efeito positivo nas terapias fonoaudiológicas analisadas, demonstrado pelo índice de mudança confiável.

Os fonoaudiólogos participantes demonstraram satisfação com a experiência da teleconsultoria assíncrona, avaliando positivamente o serviço prestado no presente estudo.

Destaca-se, pois, o potencial papel da teleconsultoria assíncrona na melhoria da qualidade dos serviços fonoaudiológicos ofertados à população infantil com deficiência auditiva.

As limitações do presente estudo foram, em especial, o número de sujeitos participantes e a impossibilidade de se avaliar a manutenção do efeito das teleconsultorias nas terapias dos fonoaudiólogos participantes, ao longo de um período maior de tempo, de modo a identificar qual o melhor padrão de serviço de teleconsultoria a ser ofertado (número de sessões, periodicidade, por exemplo).

Além disso, a análise da teleconsultoria síncrona também pode trazer informações importantes e complementares sobre a melhor maneira de se conduzir um serviço de teleconsultoria para fonoaudiólogos de crianças com deficiência auditiva, ponto que também pode ser melhor estudado com pesquisas envolvendo este modelo de teleconsultoria e/ou comparando ambos os modelos (síncrono e assíncrono).

Dada a importância da terapia fonoaudiológica para o processo de habilitação e reabilitação de bebês e de crianças com deficiência auditiva e suas consequências para estes sujeitos, suas famílias e para toda a sociedade, recomenda-se que estudos acerca desse tema com metodologia mais robusta (maior número de sujeitos, estudo com grupos controle, randomizados, cegos) sejam realizados.

A melhoria da qualidade da terapia fonoaudiológica Aurioral otimizará o 
investimento realizado desde o diagnóstico precoce, com impactos positivos na inclusão e na qualidade de vida da população de crianças com deficiência auditiva. 


\section{REFERÊNCIAS}

ARMIGLIATO, M. E. et al. Avaliação de serviços de saúde auditiva sob a perspectiva do usuário: proposta de instrumento. Rev. da Sociedade Brasileira de Fonoaudiologia, São Paulo, v. 15, n. 1, p. 32-39, jun. 2010.

BELL, A. G. A. Academy for Listening and Spoken Language (LSLS Cert. AVT Application - Attachment G: Auditory-Verbal Teaching Behaviors). Checklist, 2009.

BEVILACQUA, M. C.; FORMIGONI, G. M. P. Audiologia educacional: uma opção terapêutica para a criança deficiente auditiva. 3. ed. 2. reimp. São Paulo: Pró-Fono, 2012.

BRASIL. Constituição (1988). Constituição da República Federativa do Brasil. Brasília, DF: Senado Federal: 1988. 292 p.

BRASIL. Ministério da Saúde. Programa Telessaúde Brasil redes: Manual de telessaúde para a Atenção Básica/Atenção Primária à Saúde. Universidade Federal do Rio Grande do Sul- Brasília, 2012. Disponível em: <http://www.telessaudebrasil.org.br/>. Acesso em: 31 maio 2016.

BRASIL. Ministério da Saúde. Rede de Cuidados à Pessoa com Deficiência no âmbito do SUS: Instrutivos de Reabilitação Auditiva, Física, Intelectual e Visual (CER e serviços habilitados em uma única modalidade). Brasília, 2013a. Disponível em: <http://www.cosemssp. org.br/downloads/instrutivo-portaria-deficientes.pdf>. Acesso em: 12 out. 2016.

BRASIL. Manual de Telessaúde para a Atenção Básica. Atenção Primária à Saúde: Protocolo de Telerregulação de Teleconsultorias. Brasília: Ministério da Saúde; Universidade Federal do Rio Grande do Sul , 2013b. 42 p.

BUSH, M. L. et al. The Role of Telemedicine in Auditory Rehabilitation: A Systematic Review. Otol Neurotol. v. 37, n. 10, p.1466-1474, 2016. doi:10.1097/MAO.0000000000001236.

CONSELHO FEDERAL DE FONOAUDIOLOGIA - CFFa. Resolução CFFa n 427, de $1^{\circ}$ de março de 2013: Dispõe sobre a regulamentação da Telessaúde em Fonoaudiologia e dá outras providências. Brasília, DF, 1 mar. 2013. Disponível em: <http://www. fonoaudiologia.org.br/legislacaoPDF/Res\%20427-2013.pdf>. Acesso em: 14 set. 2016. 
CORREIA, A. D. M. S. et al. Teleodontologia no programa nacional telessaúde Brasil redes: relato da experiência em Mato Grosso Do Sul. Abeno-Telessaúde Brasil Redes, Mato Grosso do Sul, v. 14, n .1, p. 17-29, jul. 2014.

CRUZ, I. et al. Identification of Effective Strategies to Promote Language in Deaf Children with Cochlear Implants. Child Dev., v. 84, n. 2, p. 543-559, Mach. 2013.

FELISBERTO, E. Da teoria à formulação de uma Política Nacional de Avaliação em Saúde: reabrindo o debate. Rev. Ciência \& Saúde Coletiva, Boa Vista, PE, v. 11, n. 3, p. 553-563, abr. 2006.

FONSÊCA, R. O.; BRAZOROTO, J. S.; BALEN, S. A. Telessaúde em Fonoaudiologia no Brasil: revisão sistemática. Rev. CEFAC, Natal, RN, v. 17, n. 6, p. 2033-2043, dez. 2015.

GISMOND, J. P. et al. Asynchronous Teleconsultation in Primary Health: the experience of Rio de Janeiro State Telehealth Nucleus of the Brazilian National Program of Telehealth. J. Latin Am J telehealth, v. 4, n. 1, p. 39-44, 2017.

GRANHA, D. O.; OLIVEIRA, A. S.; RUMPF, K. Estratégias terapêuticas realizadas com crianças deficientes auditivas oralizadas: revisão de literatura. In: SILVA, P. B.; DAVI, R. H. F. Cadernos da Fonoaudiálogo. Audiologia. São Paulo: Lovise, 2008. p. 49-55.

JACOBSON, N. S.; TRUAX, P. Clinical significance: A statistical approach to defining meaningful change in psychotherapy research. J Consult Clin Psychol, v. 59, n. 1, p. 12-19, 1991.

LEITÃO, G. G. S. et al. Educational actions in human communication health: telehealth contributions in primary care. Rev. CEFAC., v. 20, n. 2, p. 182-190, 2018. doi: 10.1590/1982-0216201820210417.

LUCENA, A. M. et al.. Teleconsultorias de fonoaudiologia em um serviço público de telessaúde de larga escala. Revista CEFAC., v. 18, n. 6, p. 1395-1403, 2016.

MARCOLINO, M. S. et al. Teleconsultorias no apoio à atenção primária à saúde em municípios remotos no estado de Minas Gerais, Brasil. Rev. Panam. Salude Publica, v. 5/6, n. 35, p. 345-52, maio 2014.

MCCARTHY, M.; LEIGH, G.; ARTHUR-KELLY, M. Telepractice delivery of family-centred early intervention for children who are deaf or hard of hearing: A scoping review. Journal of Telemedicine and Telecare, p. 1-12, 2018. 
MOLINA-ALVEJONAS, D. R, et. al. A systematic review of the use of telehealth in speech, language and hearing sciences. J. Telemed Telecare, v. 21, n. 7, p. 367-376, oct. 2015.

BARBOZA DO NASCIMENTO, C. M. et al. Telespeech therapy as a continued education strategy in primary health care in the state of Pernambuco, Brazil. Rev. CEFAC., v. 19, n. 3, p. 371-380, 2017.

RAVI, R. et al. Knowledge and Perceptions of Teleaudiology Among Audiologists: A Systematic Review. J Audiol Otol., v. 22, n. 3, p. 120-127, 2018.

RIBEIRO, M. W. N. Teleconsultoria síncrona com Fonoaudiólogos atuantes em intervenção Fonoaudiólogica de crianças com deficiência auditiva: relato de casos. 60 f. 2015. Monografia (Graduação em Fonoaudiologia) - Universidade Federal do Rio Grande do Norte, Natal, 2015.

RESEGUE-COPPI, M. M. Desenvolvendo as habilidades auditivas em crianças usuárias de implante coclear: estratégias terapêuticas. 154f. 2008. Dissertação (Mestrado em Fonoaudiologia) - Universidade de São Paulo, Bauru, 2008.

SILVA, M. A. M.; LOPES, E. A. S. Conduct of Professionals' Basic Primary Care Attention After Replies of the Requested Teleconsultings. Latin Am J telehealth, v. 4, n.1, p. 82-87, 2017.

SPINARDI, A. C.; HERRERA, S. A. L.; MAXIMINO, L. P. Aspectos éticos e legais na prática da Telessaúde em Fonoaudiologia. Revista CEFAC-Scielo, Bauru, SP, v. 15, n. 4, p. 1-5, ago. 2013.

XAVIER, J. S. Teleconsultoria: Estudos clínicos sobre o desenvolvimento de crianças com deficiência auditiva: subsídios para a melhoria de sua (re) habilitação.77 f. 2014. Monografia (Graduação em Fonoaudiologia) - Universidade Federal do Rio Grande do Norte, Natal, 2014. 


\title{
ANEXO A - Parecer Consubstanciado do Comitê de Ética em Pesquisa
}

\author{
HOSPITAL UNIVERSITÁRIO \\ ONOFRE LOPES-UFRN.
}

\section{PARECER CONSUBSTANCIADO DO CEP}

\section{DADOS DO PROJETO DE PESQUISA}

Título da Pesquisa: Estudos clínicos sobre o desenvolvimento de crianças ouvintes e com deficiência auditiva, com risco para o desenvolvimento de linguagem: subsídios para (re) habilitação

Pesquisador: Joseli Soares Brazorotto

Área Temática: Versão: 4

CAAE: 22185313.4 .0000 .5292

Instituição Proponente: Hospital Universitário Onofre Lopes-HUOL/UFRN

Patrocinador Principal: FUNDACAO DE APOIO A PESQUISA DO ESTADO DO RIO GRANDE DO NORTE FAPERN

DADOS DO PARECER

Número do Parecer: 1.144 .295

Data da Relatoria: 26/06/2015

Apresentação do Projeto:

A pesquisadora apresentou uma Carta de Justificativa do Adendo em Projeto de Pesquisa, na qual justifica alterações do projeto em curso nos itens: título, objetivos, metodologia, TCLE's.

\section{Objetivo da Pesquisa:}

Objetivo Geral: Avaliar clinicamente de forma transversal e longitudinal, crianças com deficiência auditiva, ou com risco para a deficiência auditiva e desenvolvimento da linguagem, bem como as necessidades de seus familiares, professores e fonoaudiólogos. Objetivos Específicos: Traduzir e adaptar culturalmente instrumentos específicos da prática clínica fonoaudiológica para a avaliação na população de crianças com deficiência auditiva, bem como questionários e inventários para conhecer as necessidades de seus familiares, professores e fonoaudiólogos.

- Intervir, por meio de orientação fonoaudiológica, com as famílias, professores e profissionais da saúde (incluindo fonoaudiólogos) que atuam com crianças com deficiência auditiva ou com risco para o desenvolvimento da linguagem.

Continuação do Parecer: 1.144.295

\section{Avaliação dos Riscos e Benefícios:}

\section{Riscos:}

Os riscos para as crianças que serão avaliadas são mínimos e referem-se ao cansaço e algum constrangimento durante a aplicação das avaliações. Tais riscos serão minimizados com a realização de avaliações que compreendam a história clínica e contextos familiar e social das crianças e a realização das avaliações divididas em sessões curtas, nas quais serão realizadas as atividades apenas com o total consentimento e envolvimento das crianças, restringindo desta forma, qualquer possibilidade de indisposição ou constrangimento. Para os familiares, professores e fonoaudiólogos o mesmo procedimento será realizado para minimizar os riscos, sendo a aplicação aos inventários, questionários e orientações fonoaudiológicas (intervenção fonoaudiológica) única e exclusivamente vinculada à aceitação de participação e assinatura do termo de consentimento livre e esclarecido.

Benefícios:

Impactos científicos: Produção de conhecimento acerca do desenvolvimento de crianças com deficiência auditiva e de crianças com risco para o desenvolvimento da linguagem; Adaptação de protocolos para avaliação fonoaudiológica de crianças com deficiência auditiva em português; Auxílio na construção de um protocolo clínico para a (re) habilitação auditiva, a partir dos estudos clínicos realizados Impactos econômicos; Auxílio na implementação de um protocolo de intervenção (orientações fonoaudiológicas) para familiares, profissionais de saúde e professores de crianças com deficiência auditiva e/ou crianças com risco para o desenvolvimento da linguagem; Melhoria na qualidade do atendimento fonoaudiológico de crianças com deficiência auditiva nos serviços de saúde auditiva; Diminuição do custo com o número de atendimentos fonoaudiológicos, relacionado a maior efetividade do tratamento; Otimização dos recursos já disponibilizados pelo Ministério da Saúde na concessão de aparelhos de amplificação sonora individual e/ou implante coclear e na habilitação e reabilitação auditiva; A potencialização do desenvolvimento da linguagem oral das crianças com deficiência auditiva favorecerá a conclusão do processo educacional e, consequentemente, melhor inserção no mercado de trabalho tornando-se um adulto independente financeiramente e produtivo para a sociedade. Impactos sociais; melhora no processo de inclusão social e educacional de crianças com deficiência auditiva; Melhora no desempenho escolar ao longo do Desenvolvimento: Diminuição do estresse das famílias, em virtude do melhor desenvolvimento dos filhos.

Continuação do Parecer:

\section{Comentários e Considerações sobre a Pesquisa:}

A pesquisa é relevante do ponto de vista científico e de acesso a intervenção oportuna para o público alvo proposto. 


\section{Considerações sobre os Termos de apresentação obrigatória:}

Foram apresentados

\section{Recomendações:}

1 - Segundo a Carta de Justificativa da Pesquisadora não houve novo centro participante vinculado ao projeto no adendo apresentado, porém ao rever a postagem de documentos na plataforma, percebe-se que de 12.09.13 a 13.03.2015 o LAIS não estava citado enquanto instituição coparticipante, a respectiva Carta de Anuência está anexada desde 13.03.15. Em 30.04.15, passou a ser citado na Plataforma, da forma como foi solicitado pela relatoria. Chamo ainda a atenção para a existência de outra Carta de Anuência que está anexada e não é Citada na Plataforma, trata-se da Clínica Escola de Fonoaudiologia (CEF), anexada em 12.09.13. Portanto, a título de esclarecimento, gostaríamos de saber qual a inserção dessa instituição (CEF) na pesquisa, já que a pesquisadora afirma que apenas: EMJL, SUVAG, OTOCENTRO e LAIS figuram como instituições parceiras que foram fonte de coleta de dados?

2 - Cronograma, solicitamos apenas que anexe a plataforma uma DECLARAÇÃO onde compromete-se a não ter iniciado o "CONVITE AOS SUJEITOS DE PESQUISA APÓS APROVAÇÃO DA EMENDA PELO CEP E ASSINATURA DOS TCLE” - que estava programado para ocorrer entre 01.06 .15 a 30.06 de 2015, consequentemente alterando todo o restante do cronograma.

3 - O Cronograma precisa ser revisto, pois não cita as alterações ocorridas do projeto e a partir de qual momento irá coletar a informação quanto ao risco para o desenvolvimento da linguagem e nem quando será procedida a intervenção ou encaminhamento desses casos.

\section{Conclusões ou Pendências e Lista de Inadequações:}

As solicitações apresentadas nas recomendações, estão mais a título de esclarecimento do que propriamente alterações, a emenda será aprovada, porém gostaria de informar que a declaração solicitada e o esclarecimento sejam apresentados durante essa semana, o mais breve possível.

\section{Situação do Parecer:}

Aprovado

\section{Necessita Apreciação da CONEP:}

Não

\section{Considerações Finais a critério do CEP:}

1. Apresentar relatório parcial da pesquisa, semestralmente, a contar do início da mesma.

2. Apresentar relatório final da pesquisa até 30 dias após o término da mesma.

3. O CEP HUOL deverá ser informado de todos os efeitos adversos ou fatos relevantes que alterem o curso normal do estudo.

4. Quaisquer documentações encaminhadas ao CEP HUOL deverão conter junto uma Carta de Encaminhamento, em que conste o objetivo e justificativa do que esteja sendo apresentado.

5. Caso a pesquisa seja suspensa ou encerrada antes do previsto, o CEP HUOL deverá ser comunicado, estando os motivos expressos no relatório final a ser apresentado.

6. O TCLE deverá ser obtido em duas vias, uma ficará com o pesquisador e a outra com o sujeito de pesquisa.

7. Em conformidade com a Carta Circular $n^{\circ}$. 003/2011CONEP/CNS, faz-se obrigatório a rubrica em todas as páginas do TCLE pelo sujeito de pesquisa ou seu responsável e pelo pesquisador.

NATAL, 09 de Julho de 2015

Assinado por: HELIO ROBERTO HEKIS

(Coordenador)

Endereço: Avenida Nilo Peçanha, 620 - $3^{\circ}$ subsolo

Bairro: Petrópolis

UF: RN

Município: NATAL

Telefone:

(84) 33425003

Fax:(84)32023941

CEP:59.012-300

E-mail: cep_huol@yahoo.com.br 


\section{APÊNDICE A - Instrumento de Análise da Sessão Terapêutica em Audiologia Educacional}

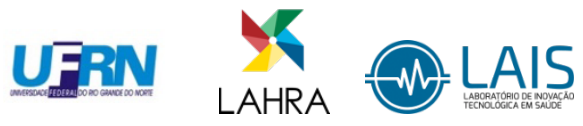

Adaptado por Brazorotto, J.S. (2014). Baseado em: AG Bell Academy for Listening and Spoken Language (LSLS Cert. AVT Application-
Attachment G: Auditory-Verbal Teaching Behaviors Checklist, 2009; Bevilacqua, M.C; Formigoni, G.M.P. Audiologia Educacional: uma
opção terapêtica para a criança deficiente auditiva; Pró-Fono, Carapicuiba,1997; Cole, E. Listening and Talking: A guide to promoting
spoken language in young hearing - impaired children, 1992.

INSTRUMENTO DE ANÁLISE DA SESSÃO TERAPÊUTICA EM AUDIOLOGIA EDUCACIONAL

Fonoaudiólogo:

Tem supervisor: ( ) sim:

( ) não

Tempo de experiência: a

$\mathrm{m}$

Data:

Instrução: A partir da observação ou análise de vídeo da sessão terapêutica marque um X no número que melhor traduz a frequência de ocorrência dos itens, usando a seguinte escala:

\begin{tabular}{|c|c|c|c|c|c|c|c|c|}
\hline \multirow{3}{*}{ Itens } & \multicolumn{7}{|c|}{ Escala } & \multirow{2}{*}{ Observações } \\
\hline & \multicolumn{5}{|c|}{ RO } & \multicolumn{2}{|c|}{ FO } & \\
\hline & 1 & 2 & 3 & 4 & 5 & 6 & 7 & \\
\hline Sensibilidade e atenção à criança & & & & & & & & \\
\hline O terapeuta segue o interesse da criança na maioria das vezes & & & & & & & & \\
\hline O terapeuta envolve a criança na atividade? & & & & & & & & \\
\hline $\begin{array}{l}\text { O terapeuta fala sobre o que a criança está fazendo ou } \\
\text { olhando? }\end{array}$ & & & & & & & & \\
\hline $\begin{array}{l}\text { O terapeuta usa adequadamente a fala, movimentos, toques } \\
\text { e/ou gestos para chamar a atenção da criança para objetos e } \\
\text { acontecimentos? }\end{array}$ & & & & & & & & \\
\hline Comunicação com a criança & & & & & & & & \\
\hline $\begin{array}{l}\text { O terapeuta reconhece as tentativas de comunicação da } \\
\text { criança e responde de forma que inclua comentários ou } \\
\text { questões, possibilitando outras respostas da criança? }\end{array}$ & & & & & & & & \\
\hline $\begin{array}{l}\text { O terapeuta dá um tempo de espera para a criança processar c } \\
\text { que foi dito e responder? }\end{array}$ & & & & & & & & \\
\hline $\begin{array}{l}\text { O terapeuta corrige e expande as produções da criança } \\
\text { semanticamente e/ou gramaticalmente e usa sinônimos? }\end{array}$ & & & & & & & & \\
\hline Coerência e integração entre metas e estratégias & & & & & & & & \\
\hline $\begin{array}{l}\text { Durante a sessão, o terapeuta desenvolve as metas } \\
\text { individualizadas estabelecidas no plano terapêutico? }\end{array}$ & & & & & & & & \\
\hline $\begin{array}{l}\text { O terapeuta focaliza a terapia no desenvolvimento da } \\
\text { linguagem por meio da audição? }\end{array}$ & & & & & & & & \\
\hline $\begin{array}{l}\text { O terapeuta mantém um ritmo apropriado na sessão (alterna } \\
\text { estratégias, apresenta dinamismo das estratégias propostas, } \\
\text { tem atenção ao tempo da criança e da família)? }\end{array}$ & & & & & & & & \\
\hline Qualidade das atividades e materiais & & & & & & & & \\
\hline $\begin{array}{l}\text { O terapeuta explora e balanceia o uso do caderno de } \\
\text { experiências, literatura infantil, músicas, jogos, na terapia? }\end{array}$ & & & & & & & & \\
\hline As estratégias chamam a atenção da criança? & & & & & & & & \\
\hline $\begin{array}{l}\text { Os materiais e brincadeiras são apropriados à faixa etária e } \\
\text { desenvolvimento da criança? }\end{array}$ & & & & & & & & \\
\hline Técnicas terapêuticas & & & & & & & & \\
\hline O terapeuta checa os dispositivos utilizando os sons de Ling? & & & & & & & & \\
\hline $\begin{array}{l}\text { O terapeuta propicia à criança a detecção e discriminação de } \\
\text { todos os sons do Português? }\end{array}$ & & & & & & & & \\
\hline O terapeuta troca de turnos com a criança? & & & & & & & & \\
\hline $\begin{array}{l}\text { O terapeuta usa padrões apropriados de voz e fala (aspectos } \\
\text { suprassegmentais e velocidade, em especial)? }\end{array}$ & & & & & & & & \\
\hline
\end{tabular}


O terapeuta incorpora músicas às estratégias e canta durante as atividades terapêuticas?

No conjunto fechado, o terapeuta manipula as variáveis de conteúdo (familiaridade, número de elementos, contrastes acústicos) e apresentação (velocidade de fala, destaques acústicos, visibilidade da frase, número de repetições?

No conjunto fechado, o terapeuta usa a sabotagem auditiva?

O terapeuta utiliza os conjuntos intermediário e aberto durante a sessão?

O terapeuta utiliza ao máximo as técnicas terapêuticas (sabotagem, sanduíche auditivo, sussurro, fechar os olhos, fechamento auditivo, destaques acústicos)?

O terapeuta utiliza as estratégias verbais quando necessário (repetir, refrasear, reforçar palavras-chaves, simplificar, correlacionar com algo já conhecido pela criança, delimitar, pedir informações)?

$\mathrm{O}$ terapeuta trabalha com a memória auditiva?

O terapeuta enfatiza as palavras de função, como artigos, pronomes, conjunções?

O terapeuta, quando apropriado ao estágio de desenvolvimento da criança, utiliza mensagem

gravada/ruído/telefone no treinamento auditivo?

\section{Família}

O terapeuta comunica-se de maneira positiva e tem efetiva interação com a família?

O terapeuta facilita a participação da família na terapia?

$\mathrm{O}$ terapeuta orienta e guia a família sobre quais as atividades devem ser executadas em casa que auxiliarão no desenvolvimento da criança?

$\mathrm{O}$ terapeuta oferece reforço positivo às atitudes de participação da família na sessão e dá feedback após a conclusão da terapia, fazendo com que esta sinta-se confiante e motivada?

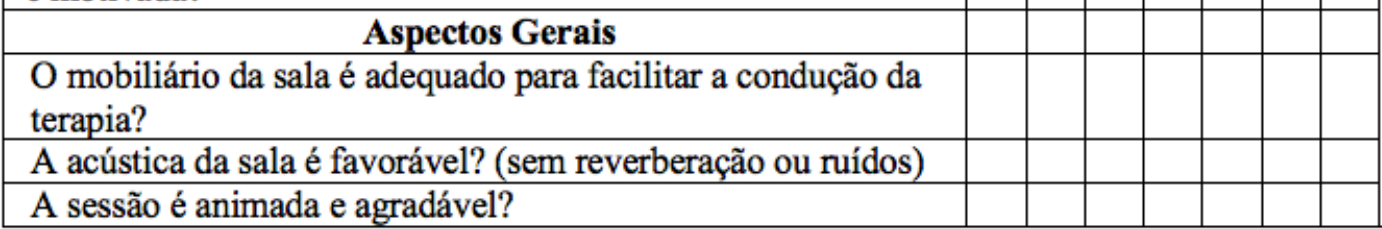

Legenda: $\mathrm{RO}=$ Raramente Observado; $\mathrm{FO}=$ Frequentemente Observado. 


\section{APÊNDICE B - Avaliação da Teleconsultoria em Audiologia Educacional}

BRASIL. Manual de Telessaúde para a Atenção Básica/Atenção Primária à Saúde: Protocolo de Telerregulação de Teleconsultorias, Ministério da Saúde, Universidade Federal do Rio Grande do Sul, Brasília, 2013. 42p.: il.

\begin{tabular}{|c|c|c|c|c|c|c|}
\hline Item & & I & $\mathbf{R}$ & B & $\mathbf{O}$ & \\
\hline 1 & $\begin{array}{l}\text { A teleconsultoria não respondeu às } \\
\text { dúvidas sobre o atendimento }\end{array}$ & & & & & $\begin{array}{l}\text { A teleconsultoria respondeu as } \\
\text { dúvidas sobre o atendimento }\end{array}$ \\
\hline 2 & $\begin{array}{l}\text { A teleconsultoria não auxiliou no } \\
\text { ajuste de técnicas, estratégias e } \\
\text { procedimentos }\end{array}$ & & & & & $\begin{array}{l}\text { A teleconsultoria auxiliou no } \\
\text { ajuste de técnicas, estratégias e } \\
\text { procedimentos }\end{array}$ \\
\hline 3 & $\begin{array}{l}\text { A linguagem do teleconsultor não } \\
\text { foi adequada para a boa } \\
\text { compreensão do conteúdo }\end{array}$ & & & & & $\begin{array}{l}\text { A linguagem do teleconsultor foi } \\
\text { adequada para a boa compreensão } \\
\text { do conteúdo }\end{array}$ \\
\hline 4 & $\begin{array}{l}\text { Na teleconsultoria não foi (ram) } \\
\text { explicitada a (s) evidência (s) } \\
\text { científica (s) para o ajuste de } \\
\text { técnicas, estratégias e } \\
\text { procedimentos }\end{array}$ & & & & & $\begin{array}{l}\text { Na teleconsultoria foi (ram) } \\
\text { explicitada a (s) evidência (s) } \\
\text { científica (s) para o ajuste de } \\
\text { técnicas, estratégias e } \\
\text { procedimentos }\end{array}$ \\
\hline 5 & $\begin{array}{l}\text { A teleconsultoria não auxiliou na } \\
\text { participação das famílias no } \\
\text { atendimento fonoaudiológico }\end{array}$ & & & & & $\begin{array}{l}\text { A teleconsultoria auxiliou na } \\
\text { participação das famílias no } \\
\text { atendimento fonoaudiológico }\end{array}$ \\
\hline 6 & $\begin{array}{l}\text { A teleconsultoria não auxiliou na } \\
\text { modificação de comportamento de } \\
\text { audição e linguagem do paciente }\end{array}$ & & & & & $\begin{array}{l}\text { A teleconsultoria auxiliou na } \\
\text { modificação de comportamento de } \\
\text { audição e linguagem do paciente }\end{array}$ \\
\hline 7 & $\begin{array}{l}\text { A teleconsultoria realizada com o } \\
\text { (s) paciente (s) não auxiliou na } \\
\text { mudança em atendimentos de } \\
\text { outros pacientes }\end{array}$ & & & & & $\begin{array}{l}\text { A teleconsultoria realizada com o } \\
\text { (s) paciente (s) auxiliou na } \\
\text { mudança em atendimentos de } \\
\text { outros pacientes }\end{array}$ \\
\hline 8 & $\begin{array}{l}\text { A teleconsultoria não foi efetiva } \\
\text { quanto ao uso da tecnologia }\end{array}$ & & & & & $\begin{array}{l}\text { A teleconsultoria foi efetiva } \\
\text { quanto ao uso da tecnologia }\end{array}$ \\
\hline 9 & $\begin{array}{l}\text { A teleconsultoria não aumentou sua } \\
\text { motivação na atuação profissional }\end{array}$ & & & & & $\begin{array}{l}\text { A teleconsultoria aumentou sua } \\
\text { motivação na sua atuação } \\
\text { profissional }\end{array}$ \\
\hline 10 & $\begin{array}{l}\text { A análise do teleconsultor não foi } \\
\text { compatível com sua auto-análise do } \\
\text { processo terapêutico }\end{array}$ & & & & & $\begin{array}{l}\text { A análise do teleconsultor não foi } \\
\text { compatível com sua auto-análise } \\
\text { do processo terapêutico }\end{array}$ \\
\hline
\end{tabular}

Legenda: $\mathbf{I}=$ insuficiente; $\mathbf{R}=$ regular; $\mathbf{B}=$ bom; $\mathbf{O}=$ ótimo 


\title{
APÊNDICE C - Modelo do TCLE
}

\author{
TERMO DE CONSENTIMENTO LIVRE E ESCLARECIDO \\ MINISTÉRIO DA EDUCAÇÃO \\ UNIVERSIDADE FEDERAL DO RIO GRANDE DO NORTE \\ TERMO DE CONSENTIMENTO LIVRE E ESCLARECIDO \\ AOS FONOAUDIÓLOGOS
}

ESCLARECIMENTOS

Este é um convite para você participar da pesquisa: "Estudo da teleconsultoria assíncrona em audiologia educacional", pesquisa que integra o estudo: ESTUDOS CLÍNICOS SOBRE O DESENVOLVIMENTO DE CRIANÇAS COM DEFICIÊNCIA AUDITIVA: SUBSÍDIOS PARA A MELHORIA DE SUA (RE) HABILITAÇÃO, o qual é coordenado pela Profa. Dra. Joseli Soares Brazorotto- CRFa 10313/SP/T/RN. A pesquisadora declara que o referido estudo cumpre com as exigências contidas nos itens IV.3 e IV.4 da Resolução no 466/12-CONEP. Sua participação é voluntária, o que significa que você poderá desistir a qualquer momento, retirando seu consentimento, sem que isso lhe traga nenhum prejuízo ou penalidade. Este projeto tem como objetivo geral avaliar a aplicabilidade da teleconsultoria no modelo assíncrono para a terapia fonoaudiólogica de crianças com deficiência auditiva. Com a realização desta, poderemos reverter benefícios para muitos outros colegas fonoaudiólogos, seus pacientes e familiares atendidos. Assim, sua participação é única, fundamental e de suma importância para que consigamos avançar no cuidado à saúde auditiva da população do estado. Caso decida aceitar o convite, suas sessões de terapia fonoaudiológica deverão ser filmadas e o registro em vídeo deverá ser encaminhado ao fonoaudiólogo teleconsultor para análise e posterior teleconsultoria. Você receberá gratuitamente materiais de estudo e consulta com sugestões de textos para leitura, caso deseje aprofundar os conhecimentos referentes à habilitação e reabilitação auditiva. Estes materiais serão encaminhados semanalmente, em assuntos definidos e de relevância para a terapia fonoaudiológica de crianças com deficiência auditiva. Os riscos envolvidos com sua participação são mínimos. O risco de constrangimento do familiar, criança ou mesmo do fonoaudiólogo pode ocorrer, mas será minimizado com interrupção da gravação quando necessário e postura ética e de sigilo absoluto sobre todos os dados discutidos na teleconsultoria. Com a sua participação na pesquisa, você terá a oportunidade de aprimorar o trabalho terapêutico desenvolvido por você na área de habilitação e reabilitação auditiva, o que trará benefícios também para seu (s) paciente (s) e sua (s) família (s). Todas as informações obtidas serão sigilosas. Os dados serão guardados em local seguro e a divulgação dos resultados será feita de forma a não identificar os voluntários.Toda a teleconsultoria será prestada gratuitamente, sem nenhum custo para você e seu(s) paciente(s) e terá duração de 3 meses (junho a agosto de 2016). Se tiver algum gasto que seja devido à sua participação na pesquisa, você será ressarcido, caso solicite. Em qualquer momento, se sofrer algum dano comprovadamente decorrente desta pesquisa, você terá direito a indenização. Você ficará com uma cópia deste termo e toda a dúvida que tiver a respeito desta pesquisa, poderá perguntar diretamente para Joseli Soares Brazorotto, no endereço Rua Monsenhor Severiano, número 547, Natal/RN, pelos telefones (84)999004777/(84)33429738 ou ainda pelo e-mail: brazorotto@yahoo.com. Dúvidas a respeito da ética dessa pesquisa poderão ser questionadas ao Comitê de Ética em Pesquisa da UFRN no endereço: Hospital Universitário Onofre Lopes, Av. Nilo Peçanha, 620 - Petrópolis Natal - RN, 59012-300 ou pelo telefone (84)33425003.

Consentimento Livre e Esclarecido

Declaro que compreendi os objetivos desta pesquisa, como ela será realizada, os riscos e benefícios envolvidos e concordo em participar voluntariamente da pesquisa "Estudo da teleconsultoria assíncrona em audiologia educacional".

Participante da pesquisa:

Pesquisador Responsável:

Joseli Soares Brazorotto

Endereço: Rua Monsenhor Severiano, número 547, Tirol, Natal-RN 